\title{
Anion-Mediated Encapsulation-Induced Emission Enhancement of an Ir' Complex within a Resorcin[4]arene Hexameric Capsule
}

Received 00th January 20xx, Accepted 00th January 20xx DOI: $10.1039 / \times 0 \times x 00000 x$

\author{
Shinnosuke Horiuchi, ${ }^{-{ }^{*}, \mathrm{~b}}$ Chiharu Matsuo, ${ }^{\mathrm{a}}$ Eri Sakuda, ${ }^{-a, b}$ Yasuhiro Arikawa, ${ }^{-a}$ Guido H. Clever \\ 가 $\mathrm{b}$ and Keisuke Umakoshi@*a
}

\begin{abstract}
Understanding of encapsulation processes in confined inner spaces of self-assembled hosts is important for the rational creation of supramolecular systems showing unusual reactivities and physical properties through molecular recognition. Herein we report the formation of luminescent supramolecular host-guest complexes consisting of a hydrogen-bonded resorcin[4]arene hexameric capsule and a variety of emissive Ir complex salts. The Ir complexes, accompanied by small counter anions $\left(\mathrm{Cl}^{-}, \mathrm{Br}^{-}, \mathrm{NO}_{2}^{-}, \mathrm{I}^{-}\right.$and $\left.\mathrm{NO}_{3}^{-}\right)$, are trapped effectively to show large encapsulation-induced emission enhancement (EIEE) behavior, while Ir complexes having large counter anions $\left(\mathrm{ClO}_{4}^{-}, \mathrm{PF}_{6}{ }^{-}\right.$and $\left.\mathrm{OTf}^{-}\right)$are not stabilized within the capsule, suggesting that the $\mathrm{Ir}$ complex cation is trapped together with its counter anion to form an ion-pair in the capsule. Hydrogenbonding capabilities of the counter anions also contribute to stabilize host-guest association, because the counter anions trapped within the capsule were in contact with the hydrophilic surfaces of the capsule.
\end{abstract}

\section{Introduction}

Self-assembly of resorcin[4]arene 1 with eight water molecules in apolar solvents affords hydrogen-bonded hexameric capsule $\mathbf{1}_{6} \bullet 8 \mathrm{H}_{2} \mathrm{O}$ with a large cavity $\left(1375 \AA^{3}\right)$, originally reported by Atwood in 1997 (Fig. 1). ${ }^{1}$ This hexameric hydrogen-bonded capsule can accommodate cationic guests in the cavity via multiple cation- $\pi$ interactions and has been successfully applied as a supramolecular catalyst for organic synthesis. ${ }^{2}$ For example, Tiefenbacher and co-workers have intensively explored a variety of enzymatic transformations of organic substrates with unusual selectivity and rate enhancements inside the hexameric capsule. ${ }^{3}$ These fascinating enzymatic systems are controlled by the drastic stabilization of cationic transition states and reaction intermediates via cation- $\pi$ interaction between guest molecules and the electron-rich hexameric capsule. Furthermore, the hexameric capsule can act as a mild Brønsted acid ( $p K_{\mathrm{a}}=5.9$ ) to perform catalytic reactions with organic compounds. It was also found that organic and organometallic catalysts can be accommodated within the capsule, providing reactivity control and unusual selectivity through encapsulation. ${ }^{4}$

Understanding of molecular recognition processes and their stabilizing/activating effect on guest molecules within the

\footnotetext{
Division of Chemistry and Materials Science, Graduate School of Engineering, Nagasaki University, Bunkyo-machi, Nagasaki, 852-8521 (Japan).

E-mail:shoriuchi@nagasaki-u.ac.jp,kumks@nagasaki-u.ac.jp

$b$ Faculty of Chemistry and Chemical Biology, TU Dortmund University, Otto-HahnStrasse 6, 44227, Dortmund, Germany.

Electronic Supplementary Information (ESI) available: Se DOI: $10.1039 / x 0 x \times 00000 x$
}

capsule are essential to design and refine new types of supramolecular catalysts for organic transformations. The cavity of the hydrogen-bonded hexameric capsule is fully covered by the resorcin[4]arene units, thus encapsulation of guests is believed to proceed via reversible dissociation of one resorcin[4]arene unit from the hexameric framework. ${ }^{5}$ Cationic organic guests are known to form ion-pairs within the capsule. ${ }^{6}$ Water molecules in the capsule structure also play vital roles in both the formation of the hexameric assembly and their guest binding. ${ }^{7}$ Recently, QM calculations reasonably explained that a hydrogen bonding interaction between substrates and bridging water molecules in the capsule framework can promote Friedel-Crafts reactions within the capsule. $^{8}$ Thus, it has been established that both the interaction between water molecules and guests inside the capsule as well as the cation- $\pi$ interaction are of importance for guest binding and reactivity.

The hexameric capsule can also accommodate emissive molecules to provide luminescent host-guest systems. ${ }^{9}$ We have recently developed luminescent supramolecular hostguest complexes based on the resorcin[4]arene hexameric capsule and phosphorescent coordination complexes. ${ }^{10}$ Our approach allows to establish a new type of emissive supramolecular system which show encapsulation-induced emission enhancement (EIEE) behavior, that is, significant improvements of emission energies, luminescent quantum yield and emission lifetime of encapsulated guests within the self-assembled molecular hosts. ${ }^{11}$ It is important to note that hexameric capsule $\mathbf{2}$ does not work as a molecular optical filter or energy/electron acceptor, which would spoil the luminescence efficiency of entrapped molecules within the 
capsules, because the capsule does not absorb visible light and its cavity is fully covered by electron-rich aromatic walls. Thus, this supramolecular system provides a suitable platform for novel emissive host-guest systems to show interesting photophysical properties.

Through our recent studies of the luminescent supramolecular system of $\mathbf{2}$ encapsulating a variety of iridium complex salts $\left[\operatorname{Ir}(\mathrm{ppy})_{2}(\mathrm{bpy})\right] \mathrm{X}$, we found that the counter anion $X$ played an important role to stabilize the host-guest structure. Herein we report the vital role of counter anions toward both formation of the supramolecular structure and molecular recognition of the iridium complex cation within the resorcin[4]arene hexameric capsule. These findings will provide better understanding of fundamental aspects of the studied host-guest system and allow to progress their application as new types of supramolecular catalysts and luminescent materials based on the hexameric capsule.

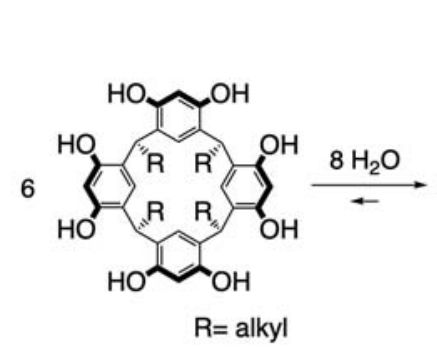

1

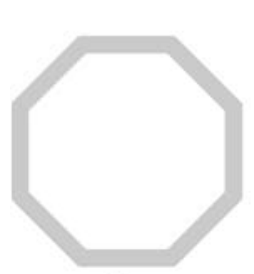

2

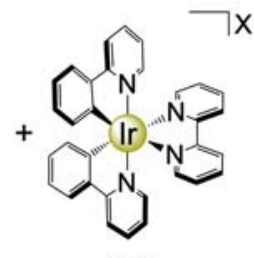

[3]X
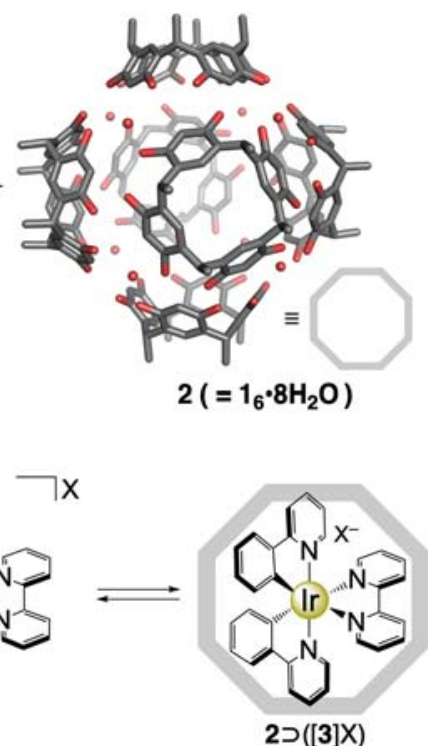

$2 \supset([3] X)$
Fig. 1 Self-assembly of resorcin[4]arene 1 forming hexameric capsule 2 and anion-dependent encapsulation of Ir complex salt [3]X within the capsule.

\section{Results and discussion}

\section{Encapsulation of an Ir'l' complex salt}

The encapsulation behavior of the bromide salt of Ir complex, $\left[\operatorname{Ir}(\mathrm{ppy})_{2}(\mathrm{bpy})\right] \mathrm{Br}([3] \mathrm{Br})$, within the hexameric hydrogenbonded capsule 2 was investigated (Scheme 1). When a 1: 6 mixture of bromide salt [3] $\mathrm{Br}$ and resorcin[4]arene with long alkyl chains $\left(\mathrm{R}=\mathrm{C}_{11} \mathrm{H}_{23}\right)$ (1a) were dissolved in wet $\mathrm{CDCl}_{3}(10$ $\mathrm{mM}$ for [3] Br) and the solution was heated at 50 oc for $1 \mathrm{~h}$, encapsulation of [3] $]^{+}$within 2 a proceeded to afford host-guest complex 2a $\supset[3] \mathrm{Br}$. The signals of $[3]^{+}$in the ${ }^{1} \mathrm{H}$ NMR spectra were considerably shifted to up-field region ( $\Delta \delta \approx-1.5 \mathrm{ppm}$ ) and broadened significantly owing to the shielding effect from the aromatic wall of the capsule and the rapid tumbling of [3] $]^{+}$ in 2a (Fig. 2a,b). The diffusion-ordered spectroscopy (DOSY) NMR spectrum showed a single band at diffusion coefficient ( $D$ $=4.4 \pm 0.6 \times 10^{-10} \mathrm{~m}^{2} \mathrm{~s}^{-1}$ ) and significant reduction from the diffusion coefficient of $[3]^{+}\left(\Delta D \approx-4.6 \times 10^{-10} \mathrm{~m}^{2} \mathrm{~s}^{-1}\right)$, suggesting the complex cation was accommodated in the capsule to form the host-guest complex. The addition of tetrabutylammonium bromide [TBA]Br as a competitive cationic guest into the solution of $2 \mathrm{a} \supset[\mathbf{3}] \mathrm{Br}$ showed guest exchange reaction without heating to release the complex cation [3] ${ }^{+}$smoothly from the cavity. The ${ }^{1} \mathrm{H}$ NMR spectrum recorded after the addition of [TBA]Br exhibited that the signals corresponding to free $[3]^{+}$were recovered and new broadening signals which can be assigned to the entrapped ammonium salt were observed at around 0 ppm (Fig. 2c). These results indicate that the ammonium salt [TBA]Br has better binding capabilities than [3] Br toward the aromatic walls inside the capsule. It is noted that the encapsulation of [3] Br takes several days to reach a state of equilibrium at room temperature. The heating condition significantly accelerated the encapsulation process, probably because the encapsulation of guests proceeded through the portal of the capsule produced by a reversible dissociation of 1a from the hexameric capsule framework at elevated temperature. ${ }^{5}$

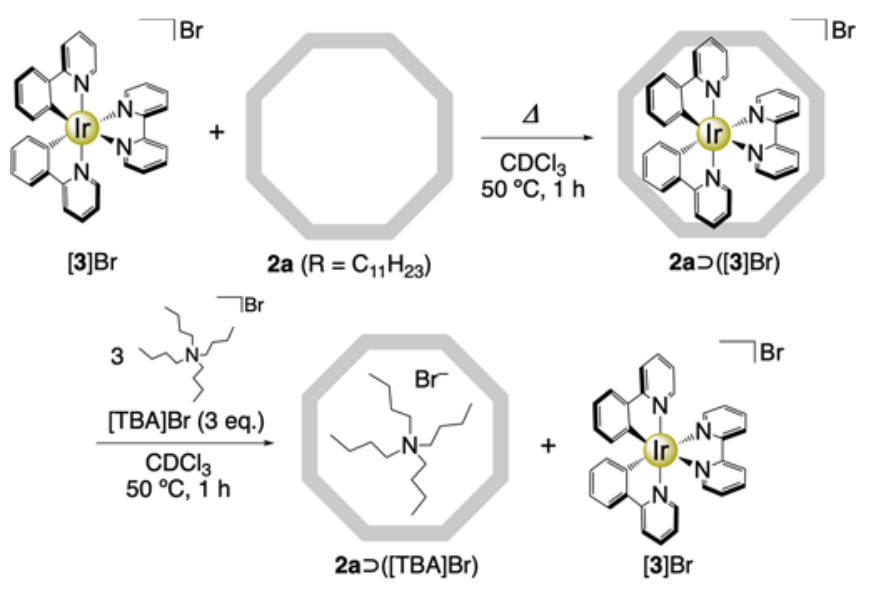

Scheme 1 Encapsulation of [3]Br within the resorcin[4]arene hexameric capsule and the guest exchange of $2 \mathrm{a} \supset[\mathbf{3}] \mathrm{Br}$ with tetrabutylammonium bromide ([TBA]Br).

(a)

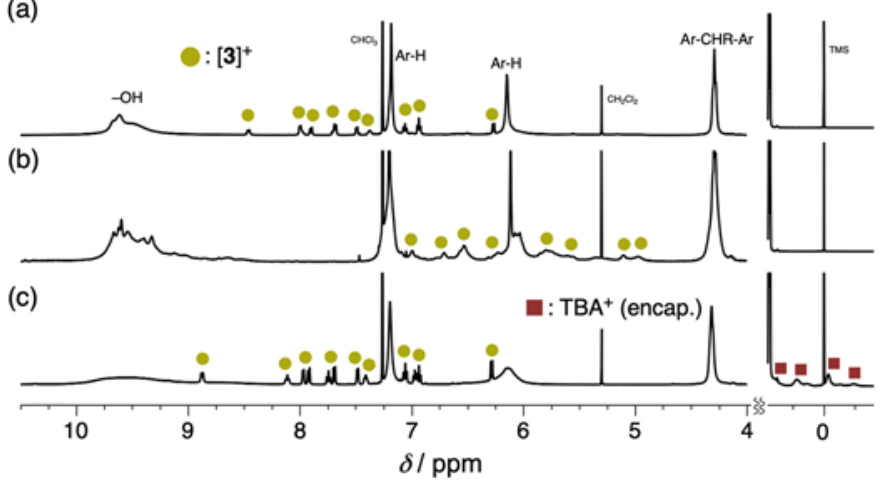

Fig. $2{ }^{1} \mathrm{H}$ NMR spectra $\left(500 \mathrm{~Hz}, \mathrm{CDCl}_{3}\right.$, r.t.) of the mixture of [3] $\mathrm{Br}$ and $\mathbf{2 a}$ in a $1: 6$ ratio (a) before heating, (b) after heating at $50{ }^{\circ} \mathrm{C}$ for $1 \mathrm{~h}$, and (c) after further addition of [TBA] $\mathrm{Br}$ (3 eq.). 
To gain further insights into host-guest association, we performed ESI-MS analysis. Schalley et al. reported that ESI-MS techniques can give helpful evidences for the structure of host-guest complexes of resorcin[4]arene hexameric capsules in the gas-phase. ${ }^{12}$ When resorcin[4]arene $\mathbf{1 b}$, having short alkyl chains $(R=M e)$, was ionized with an electrospray ionization (ESI) source in the absence of Ir complex cation [3] $]^{+}$, only the cationic sodium adduct of monomer $\mathbf{1} \mathbf{b}$ was observed in the mass spectrum. On the other hand, the mass spectra of 1b in the presence of the Ir complex salts clearly showed formation of host-guest complexes $\left[\mathbf{1}_{n} \cdot \mathbf{3}\right]^{+}(n=1 \sim 6)$ in the gas-phase (Fig. 3a). The mixture of $\mathbf{1 b}$ and $[\mathbf{3}]^{+}$in $\mathrm{CHCl}_{3}$ /acetone (2:1) showed intense signals at $\mathrm{m} / \mathrm{z}$ 1201.3, 1746.6, 2290.8, 2835.0, 3380.2, and 3924.4, which correspond to $[\mathbf{1 b} \cdot \mathbf{3}]^{+},\left[\mathbf{1} \mathbf{b}_{\mathbf{2}} \cdot \mathbf{3}\right]^{+},\left[\mathbf{1} \mathbf{b}_{\mathbf{3}} \cdot \mathbf{3}\right]^{+},\left[\mathbf{1} \mathbf{b}_{\mathbf{4}} \cdot \mathbf{3}\right]^{+},\left[\mathbf{1} \mathbf{b}_{5} \cdot \mathbf{3}\right]^{+}$, and $\left[\mathbf{1} \mathbf{b}_{6} \cdot \mathbf{3}\right]^{+}$, respectively. Thus, the cation- $\pi$ interactions between resorcin[4]arene aggregates $\mathbf{1} \mathbf{b}_{\mathbf{n}}$ and the Ir complex cation [3] ${ }^{+}$ support the associated structure even in the gas-phase. Notably, the most intense signal is assigned to the host-guest complex $\left[\mathbf{1 b}_{\mathbf{3}} \cdot \mathbf{3}\right]^{+}$at $\mathrm{m} / \mathrm{z} \mathbf{2 2 9 0 . 8}$, suggesting that the hostguest complex $\mathbf{2} \mathbf{b} \supset[\mathbf{3}]^{+}\left(\left[\mathbf{1} \mathbf{b}_{6} \bullet \mathbf{3}\right]^{+}\right)$readily shows fragmentation during the measurement conditions. Tandem mass spectrometry (ESI-MS/MS) clearly showed fragmentation from the parent peak $\left[\mathbf{1}_{\mathbf{4}} \cdot \mathbf{3}\right]^{+}$by consecutive losses of resorcin[4]arene monomers with peaks corresponding to $\left[\mathbf{1 b}_{\mathbf{3}} \cdot \mathbf{3}\right]^{+},\left[\mathbf{1} \mathbf{b}_{\mathbf{2}} \cdot \mathbf{3}\right]^{+},[\mathbf{1} \mathbf{b} \cdot \mathbf{3}]^{+}$, and $[\mathbf{3}]^{+}$, respectively (Fig. 3b). With increasing collision gas energy, the fragmentation afforded smaller fragments (Fig. S16).

(a)

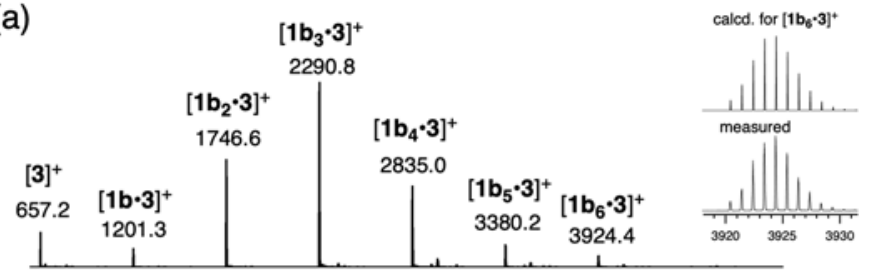

(b)

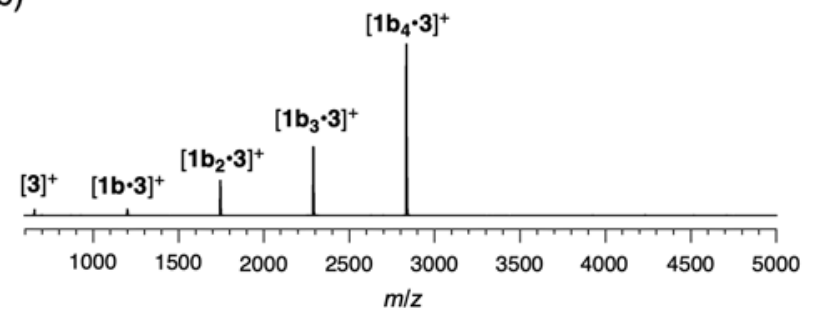

Fig. 3 (a) ESI mass spectrum of a mixture of Ir complex $[3]^{+}$and resorcin[4]arene $\mathbf{1 b}$ in $\mathrm{CHCl}_{3}$ /acetone (2:1). (b) ESI tandem mass spectrum of $\left[\mathbf{1}_{\mathbf{4}} \cdot \mathbf{3}\right]^{+}(\mathrm{m} / \mathrm{z}: \mathbf{2 8 3 5}$, collision energy: $5 \mathrm{eV})$

\section{Encapsulation-induced emission enhancement}

Photoluminescence of $[\mathbf{3}]^{+}$is mainly derived from emission from the mixed ${ }^{3} \mathrm{LLCT} /{ }^{3} \mathrm{MLCT}$ excited states, which are sensitive to the local environment such as solvent polarity and rigidity. ${ }^{13}$ Thus the emission properties of [3] $]^{+}$were modulated within the capsule owing to the effective separation from bulk solvent by encapsulation. ${ }^{10 a, 14}$ The emission color of [3] $\mathrm{Br}(10$ $\mu \mathrm{M})$ changed from orange $\left(\lambda_{\mathrm{em}}=608 \mathrm{~nm}\right)$ to yellow $\left(\lambda_{\mathrm{em}}=593\right.$ $\mathrm{nm})$ in the presence of 1a (60 $\mu \mathrm{M}, 6$ eq.), showing a blue-shift $\left(\Delta \lambda_{\mathrm{em}}=-15 \mathrm{~nm}\right)$ of the spectrum (Fig. 4). The quantum yield $(\Phi)$ and the lifetime $(\tau)$ of the emission also increased by encapsulation from $23 \%$ ( $\tau=430 \mathrm{~ns}$ ) to $28 \%$ ( $\tau_{\text {ave }}=870 \mathrm{~ns}$ ). These results clearly demonstrate that this host-guest system can show encapsulation-induced emission enhancement (EIEE) behavior. It is noted that the non-radiative rate of $[3]^{+}\left(k_{\mathrm{nr}}=\right.$ $\left.1.8 \times 10^{6} \mathrm{~s}^{-1}\right)$ was reduced significantly by encapsulation $\left(k_{\mathrm{nr}}=\right.$ $\left.0.83 \times 10^{6} \mathrm{~s}^{-1}\right)$, indicating that non-radiative pathways caused by solvent quenching and dynamic behavior of [3] $]^{+}$in solution were inhibited within the cavity. ${ }^{15}$ The electron-rich hexameric capsule protected the excited guest generated by photoirradiation, resulted in the observation of longer emission lifetime after encapsulation. These stabilization effects for the reactive species are one of the most fascinating results in these host-guest systems. ${ }^{16}$ As increasing the amount of $1 \mathrm{a}(300 \mu \mathrm{M}, 30$ eq. $)$, the emission properties of [3] ${ }^{+}$ were further improved $\left(\lambda_{\mathrm{em}}=580 \mathrm{~nm}, \Phi=34 \%, \tau_{\text {ave }}=970 \mathrm{~ns}\right)$, because the host-guest association was controlled by two equilibrium reactions: the self-assembly of $\mathbf{1 a}$ and encapsulation of $[\mathbf{3}]^{+}$into $\mathbf{2 a}$. Larger amounts of $\mathbf{1 a}$ shift the encapsulation equilibrium toward the host-guest assembly. The non-radiative rate of the mixture was further reduced and became constant $\left(k_{\mathrm{nr}}=0.68 \times 10^{6} \mathrm{~s}^{-1}\right)$ upon the addition of large amounts of 1a (30 eq.), indicating that the host-guest structure was stabilized under this condition and thus the protection effect by the capsule was enhanced significantly.

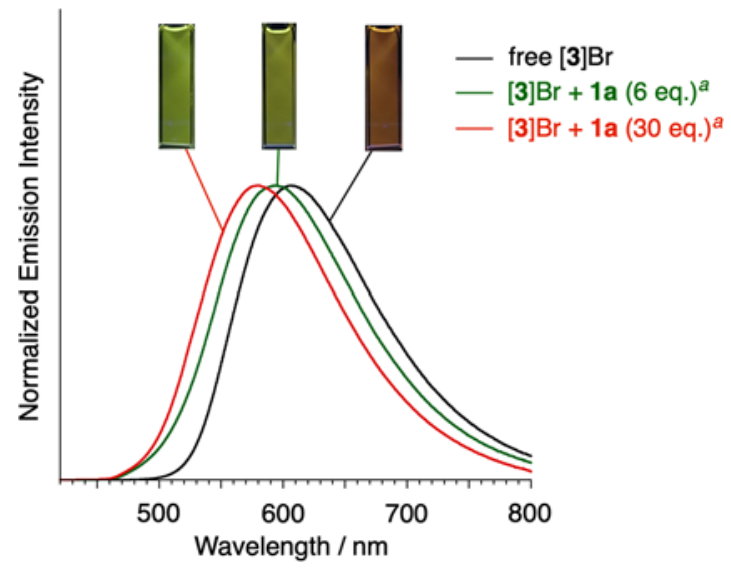

Fig. 4 Normalized emission spectra of [3] $\mathrm{Br}(10 \mu \mathrm{M})$ with various amounts of resorcin[4]arene monomer $1 \mathrm{a}(0,60$, and $300 \mu \mathrm{M}) . \lambda_{\mathrm{ex}}=400 \mathrm{~nm}$. ${ }^{a}$ After encapsulation by heating at $50^{\circ} \mathrm{C}$.

\section{Effect of anions}

We examined the formation of the host-guest complex using iridium complex salts having a variety of counter anions. Since the host-guest structure $\mathbf{2} \mathbf{a} \supset[\mathbf{3}]^{+}$is expected to be stabilized by cation- $\pi$ interaction between hexameric capsule $\mathbf{2} \mathbf{a}$ and the Ir complex cation [3] $]^{+}$in solution, as observed in the ESI-MS results of [3]Br, the formation of host-guest complex $2 \mathrm{a} \supset[3]^{+}$ should be irrespective of counter anions. Very interestingly, however, an anion-dependent formation of the host-guest 
assembly was observed. For example, when a 1:6 mixture of [3] $\mathrm{PF}_{6}$ and $1 \mathrm{a}$ in wet $\mathrm{CDCl}_{3}(10 \mathrm{mM})$ was heated at $50 \circ \mathrm{C}$ for $2 \mathrm{~h}$, no significant change was observed in the ${ }^{1} \mathrm{H}$ NMR spectrum (Fig. S10). Similarly, the emission peak of [3] $\mathrm{PF}_{6}(10 \mu \mathrm{M}$ in $\mathrm{CHCl}_{3}$ ) did not shift even in the presence of large amounts (30 eq.) of 1a (Fig. S30). These results indicate that [3]PF 6 is not trapped within $\mathbf{2 a}$ and strongly suggest that the anions participate in the formation of the host-guest assembly and control the encapsulation equilibrium.

Based on the photophysical analysis as discussed above, the emission wavelength of the $\mathrm{Ir}$ complex cation [3] $]^{+}$is responsive to the encapsulation equilibrium of $\mathbf{2 a} \supset[\mathbf{3}]^{+}$. As the emission spectra of the free Ir complex cation [3] $]^{+}$recorded in $\mathrm{CHCl}_{3}(10$ $\mu \mathrm{M}$ ) were found to be independent on the counter anion (Fig. S17), the blue shift of the emission maximum $\left(\lambda_{\max }\right)$ upon addition of the hexameric capsule can serve as an indicator for the preference of the host-guest assembly process. The photophysical data for a variety of Ir complex salts [3]X (X $=\mathrm{Cl}$, $\mathrm{Br}, \mathrm{I}, \mathrm{NO}_{2}, \mathrm{NO}_{3}, \mathrm{BF}_{4}, \mathrm{PF}_{6}, \mathrm{OTf}$ ) in the presence of $1 \mathrm{a}$ (30 eq.) are listed in Table 1, showing that the emission energies of encapsulated complex cations are dependent on the size of the counter anion. The largest blue shift $\left(\Delta \lambda_{\max }=-36 \mathrm{~nm}\right)$ was observed for the smallest anion, $\mathrm{Cl}^{-}\left(V=24 \AA^{3}\right)$, while negligible shifts were observed for the large anions, $\mathrm{PF}_{6}{ }^{-}$and OTf $^{-}\left(\mathrm{V}=75\right.$ and $85 \AA^{3}$, respectively). ${ }^{17}$ It was reported before that organic cations can be encapsulated together with their counter anions to form ion-pairs within the resorcin[4]arene hexameric capsule. ${ }^{6}$ Owing to the rigid framework of the $\mathrm{Ir}$ complex cation $[3]^{+}$, small anions were suspected to be capable of forming ion-pairs $2 \mathrm{a} \supset([3] \mathrm{X})$ within the hexameric capsule rather than cation-trapping structure $(\mathbf{2} a \supset[3]) X$, leading to the large blue-shift of the emission. These results strongly suggest that the host-guest assembly $2 \mathrm{a} \supset([3] \mathrm{X})$ was stabilized by the ion-pair formation of guest salts more effectively than cation- $\pi$ and $\mathrm{CH}-\pi$ interactions between the guest cation and the aromatic wall in the capsule.

\section{Modeling study}

Modeling the structure of $\mathbf{2} \supset[\mathbf{3}]^{+}$, in which the geometries of resorcin[4]arene capsule $\mathbf{2}$ and guest [3] ${ }^{+}$were based on their individual X-ray structures, clearly showed the rather snug fit of the octahedral Ir complex cation within the hexameric capsule and scattered portions of free inner void space around the guest (Fig. 5). The volumes of these residual small cavities in $\mathbf{2} \supset[\mathbf{3}]^{+}$estimated by the VOIDOO calculation were approximately $40-70 \AA^{3}$ each, indicating that the spaces were still large enough to accommodate small guests together with the Ir complex cation. ${ }^{18}$ These results suggest that the hexameric capsule possesses a cavity large enough to trap both the complex cation and the counter anion to form an ionpair in the inner space. It is noted that these residual spaces are located nearby hydroxyl $(-\mathrm{OH})$ groups and $\mathrm{H}_{2} \mathrm{O}$ molecules in the capsule framework (Fig. 5b). Thus, hydrogen-bonding interactions are expected to contribute capturing the counter anions to promote the formation of ion-pairs within the capsule. In fact, the hydrogen-bonding capability of the examined counter anions was observed to affect the thermodynamic stability of the host-guest complexes. For example, $\mathrm{NO}_{3}{ }^{-}$ion is reported to be a better hydrogen-bond acceptor than $\mathrm{I}^{-}$ion (Table S1), ${ }^{19}$ showing the larger blue shift of the emission after encapsulation, although the size of $\mathrm{NO}_{3}{ }^{-}$ ion is larger than that of the $\mathrm{I}^{-}$ion (Table 1). Thus, the stronger hydrogen-bonding capability of anions compensated the thermodynamic stability of the assembled structure accommodating the larger counter anions.
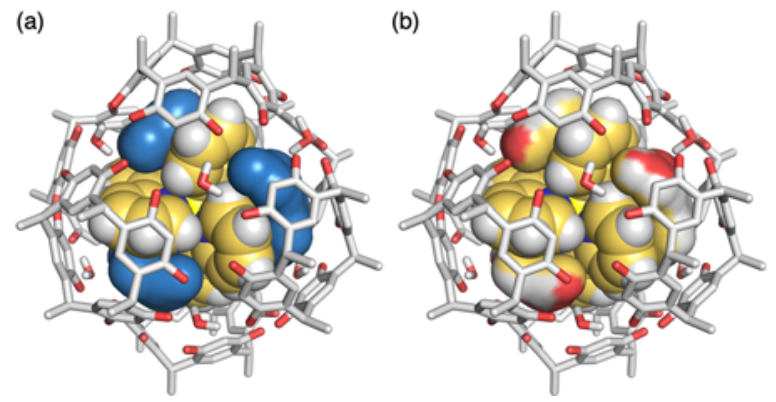

Fig. 5 A modeled structure of $\mathbf{2} \supset[\mathbf{3}]^{+}$with residual inner spaces. Hexameric capsule $\mathbf{2}$ is depicted by thick sticks, Ir complex cation [3] $]^{+}$by space-filling model. The residual inner spaces around the Ir complex cation within the capsule, where the co-encapsulated anions and solvent molecules can locate, are shown in (a) blue spheres, and (b) spheres with the same colors as the neighboring atoms to show which atoms are close to the residual

Table 1 Photophysical data $\left(10 \mu \mathrm{M}\right.$, r.t., $\left.\mathrm{CHCl}_{3}\right)$ of [3]X in the absence and presence of resorcin[4]arene 1a (30 eq.). ${ }^{a}$

\begin{tabular}{llllll} 
Compound & $\lambda_{\max }^{\text {free }}(\mathrm{nm})$ & $\lambda_{\max }^{\text {encap }}(\mathrm{nm})$ & $\Delta \lambda_{\max }(\mathrm{nm})$ & Anion size $\left(\AA^{3}\right)^{b}$ & $\begin{array}{l}\mathrm{H} \text {-bond acceptor } \\
\text { parameters }(\beta)^{c}\end{array}$ \\
\hline$[3] \mathrm{Cl}{ }^{d}$ & 609 & 573 & -36 & 24 & $12.1 \pm 0.3$ \\
{$[3] \mathrm{Br}$} & 608 & 580 & -28 & 28 & $10.6 \pm 0.2$ \\
{$[3] \mathrm{NO}_{2}$} & 607 & 576 & -31 & 32 & - \\
{$[3] !$} & 605 & 579 & -26 & 35 & $9.1 \pm 0.1$ \\
{$[3] \mathrm{NO}_{3}$} & 606 & 578 & -28 & $41^{e}$ & $10.7 \pm 0.5$ \\
{$[3] \mathrm{BF}_{4}$} & 605 & 591 & -14 & 53 & - \\
{$[3] \mathrm{ClO}_{4}$} & 605 & 601 & -4 & 55 & $8.3 \pm 0.4$ \\
{$[3] \mathrm{PF}_{6}$} & 604 & 603 & -1 & 75 & $7.0 \pm 0.3$ \\
{$[3] \mathrm{OTf}^{d}$} & 604 & 604 & 0 & 85 & $9.4 \pm 0.4$
\end{tabular}

${ }^{a}$ All measurements were performed in $\mathrm{CHCl}_{3}$ at room temperature under degassed conditions $\left(\lambda_{\mathrm{ex}}=400 \mathrm{~nm}\right) .{ }^{b}$ ref.17. ${ }^{c}$ ref.19. ${ }^{d}$ ref.10a. ${ }^{e}$ calculated by a DFT calculation. 
spaces.

The behavior of counter anions in the encapsulation process within capsule $\mathbf{2}$ was also carefully monitored by NMR spectroscopies. The protons at 3,3'-positions on the bipyridine ligands in $[3]^{+}$are relatively acidic and can trap anions via hydrogen bonds. ${ }^{20}$ Therefore, the chemical shifts of the $3,3^{\prime}$ protons on the bpy ligand also serve as an indicator of the anions in solution. For example, the ${ }^{1} \mathrm{H}$ NMR spectrum of $\mathrm{Ir}$ complex salt [3] Br showed a doublet signal at $9.65 \mathrm{ppm}$, which corresponds to the protons at 3,3'-positions (Fig. S14). This proton signal at the highly downfield region indicates that the 3,3'-protons form hydrogen bonds with a $\mathrm{Br}$ anion in $\mathrm{CHCl}_{3}$. The doublet signals shifted considerably to higher frequency ( $\Delta \delta \approx-1.1 \mathrm{ppm}$ ) upon addition of resorcin[4]arene 1a, suggesting that the $\mathrm{Br}$ anion was separated from the bpy ligands (Fig. 2a). As the hexameric capsule can work as a strong hydrogen-bond donor owing to its mild acidity, the $\mathrm{Br}$ anion was presumably captured by the hexameric capsule. The addition of $[\mathrm{TBA}] \mathrm{Br}$ salt into the solution of the host-guest complex $2 \mathrm{a} \supset([3] \mathrm{Br})$ resulted in the down-field shift of the 3,3'protons on the bpy ligand, indicating that free $\mathrm{Br}$ anion was trapped again by the free Ir complex cation (Fig. 2c). ${ }^{21}$ Similarly, ${ }^{1} \mathrm{H}$ NMR spectra of [3]PF, whose anion is recognized as a poor hydrogen-bond acceptor, ${ }^{19}$ did not show a significant change in the aromatic regions upon an addition of the capsule (Fig. $\mathrm{S} 10$ ), as well as no change in their ${ }^{19} \mathrm{~F}$ NMR spectra (Fig. S11). ${ }^{22}$ These results also support that both the size and hydrogen bond acceptability of the anions control the encapsulation equilibrium of Ir complex cation [3] ${ }^{+}$within the large cavity of $\mathbf{2}$.

\section{Proposed encapsulation mechanism}

Based on these NMR and photophysical studies, we propose a plausible encapsulation mechanism as is shown in Scheme 2. Addition of resorcin[4]arene $\mathbf{1}$ into a wet chloroform solution of Ir complex salt [3]X immediately causes self-assembly of hexameric capsule $\mathbf{2}$ and a subsequent binding of the counter anions of [3]X with outer surface of the capsule via hydrogenbonding, ${ }^{23}$ affording a mixture of anionic capsule and free Ir complex cation (Fig. 2a). As the hexameric structure is stabilized by multiple hydrogen bonds, heating accelerates dissociation of resorcin[4]arene monomers from the hexameric assembly to trigger guest encapsulation. If the size of the anion is adequate to form an ion-pair within the capsule, the host-guest complex $\mathbf{2} \supset([\mathbf{3}] \mathrm{X})$ is drastically stabilized, showing a higher-energy luminescence from the Ir complex cation [3] $]^{+}$. In contrast, the state of encapsulation equilibrium changes corresponding to the size of anion, if it is comparable to or larger than the residual inner spaces in $2 \supset[\mathbf{3}]^{+}$. In addition, the inner space in $\mathbf{2} \supset[\mathbf{3}]^{+}$is lined with hydrophilic groups and thus only anions capable to form strong hydrogen bonds are effectively trapped in the cavity to increase the thermodynamic stability of the host-guest assembly.

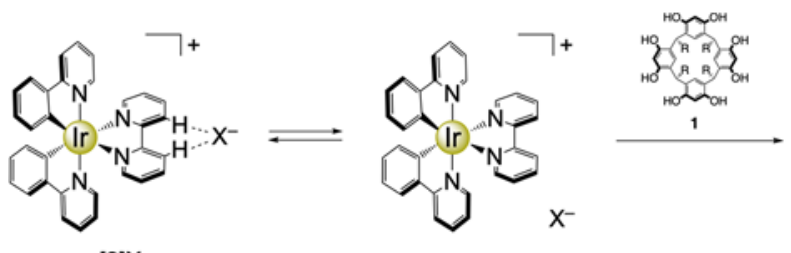

$[3] \mathrm{X}$

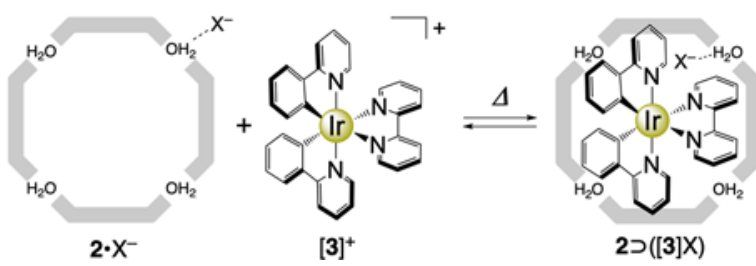

Scheme 2 A plausible mechanism for the formation of the host-guest complex $2 \supset([3] X)$. The Ir complex cation was trapped together with its anion to form an ion-pair in the capsule, controlling the thermodynamic stability of the supramolecular assembly in the encapsulation equilibrium.

\section{Conclusions}

In summary, we investigated the anion-promoted formation of host-guest complexes consisting of a hydrogen-bonded hexameric capsule and luminescent coordination complex salts. When Ir complex cation are trapped in the resorcin[4]arene hexameric capsule, their luminescent properties are altered to show higherenergy emission, compared to those from the free complex salt in solution. The resorcin[4]arene hexameric capsule has been realized to accommodate cationic guests owing to multiple cation-? interaction, as observed in ESI-MS studies. However, the spectroscopic studies in this paper clearly showed that counter anions played a crucial role to form the host-guest assembly and enabled us to propose the encapsulation process within the hydrogen-bonded hexameric capsule. In particular, hydrogen-bond capabilities of the anions contributed clearly to the thermodynamic stability of the supramolecular host-guest formation. These findings will lead us to further rational designs of new types of supramolecular catalysts and luminescent materials based on the hexameric capsules.

\section{Conflicts of interest}

There are no conflicts to declare.

\section{Acknowledgements}

This research was supported by JSPS KAKENHI Grant Numbers 17K14463, 19K15589, 19H04587, 20H05231, and by the priority research project in Nagasaki University, the JGC-S Scholarship Foundation, the Noguchi Institute, the Ogasawara Foundation for the Promotion of Science \& Engineering, and the Izumi Science and Technology Foundation. S.H. and E.S. thank the JSPS Program for Advancing Strategic International Networks to Accelerate the Circulation on Talented Researchers. This work was supported by the Research Training group 'Confinement-controlled Chemistry', funded by the Deutsche Forschungsgemeinschaft (DFG) under Grant GRK2376/ 331085229. This work was a result of using research 
equipment shared in MEXT project for promoting public utilization of advanced research infrastructure (Program for supporting introduction of the new sharing system) Grant Number JPMXS0422500320.

\section{Notes and references}

1 L. R. MacGillivray, J. L. Atwood, Nature 1997, 389, 469-472.

2 (a) L. Catti, Q. Zhang, K. Tiefenbacher, Chem. Eur. J. 2016, 22, 9060-9066; (b) C. R. Kennedy, S. Lin, E. N. Jacobsen, Angew. Chem. Int. Ed. 2016, 55, 12596-12624; (c) Y. Zhu, J. Rebek, Jr., Y. Yu, Chem. Commun. 2019, 55, 3573-3577; (d) C. Gaeta, C. Talotta, M. D. Rosa, P. L. Manna, A. Soriente, P. Neri, Chem. Eur. J. 2019, 25, 4899-4913.

3 (a) Q. Zhang, K. Tiefenbacher, J. Am. Chem. Soc. 2013, 135, 16213-16219; (b) Q. Zhang, K. Tiefenbacher, Nature Chem. 2015, 7, 197-202; (c) L. Catti, K. Tiefenbacher, Chem. Commun. 2015, 51, 892-894; (d) Q. Zhang, L. Catti, J. Pleiss, K. Tiefenbacher, J. Am. Chem. Soc. 2017, 139, 11482-11492; (e) L. Catti, K. Tiefenbacher, Angew. Chem. Int. Ed. 2018, 57, 14589-14592; (f) Q. Zhang, L. Catti, K. Tiefenbacher, Acc. Chem. Res. 2018, 51, 2107-2114; (g) Q. Zhang, K. Tiefenbacher, Angew. Chem. Int. Ed. 2019, 58, 12688-12695.

4 (a) A. Cavarzan, A. Scarso, P. Sgarbossa, G. Strukul, J. N. H. Reek, J. Am. Chem. Soc. 2011, 133, 2848-2851; (b) G. Bianchini, A. Scarso, G. L. Sorella, G. Strukul, Chem. Commun. 2012, 48, 12082-12084; (c) A. C. H. Jans, A. Gómez-Suárez, S. P. Nolan, J. N. H. Reek, Chem. Eur. J. 2016, 22, 14836-14839; (d) T. M. Bräuer, Q. Zhang, K. Tiefenbacher, Angew. Chem. Int. Ed. 2016, 55, 7698-7701; (e) T. M. Bräuer, Q. Zhang, K. Tiefenbacher, J. Am. Chem. Soc. 2017, 139, 17500-17507.

5 (a) M. Yamanaka, A. Shivanyuk, J. Rebek, Jr., J. Am. Chem. Soc. 2004, 126, 2939-2943; (b) L. Avram, Y. Cohen, J. Rebek, Jr., Chem. Commun. 2011, 47, 5368-5375.

6 (a) A. Shivanyuk, J. Rebek, Jr., Proc. Natl. Acad. Sci. USA 2001, 98, 7662-7665; (b) Q. Zhang, L. Catti, V. R. I. Kaila, K. Tiefenbacher, Chem. Sci. 2017, 8, 1653-1657.

7 (a) L. Avram, Y. Cohen, J. Am. Chem. Soc. 2002, 124, 1514815149; (b) L. Avram, Y. Cohen, Org. Lett. 2002, 4, 4365-4368; (c) T. Evan-Salem, I. Baruch, L. Avram, Y. Cohen, L. C. Palmer, J. Rebek, Jr. Proc. Natl. Acad. Sci. USA 2006, 103, 1229612300; (d) A. Katiyar, J. C. F. Sovierzoski, P. B. Calio, A. A. Vartia, W. H. Thompson, Chem. Commun. 2019, 55, 65916594.

8 (a) P. L. Manna, C. Talotta, G. Floresta, M. D. Rosa, A. Soriente, A. Rescifina, C. Gaeta, P. Neri, Angew. Chem. Int. Ed. 2018, 57, 5423-5428; (b) S. Gambaro, M. D. Rosa, A. Soriente, C. Talotta, G. Floresta, A. Rescifina, C. Gaeta, P. Neri, Org. Chem. Front. 2019, 6, 2339-2347; (c) P. L. Manna, M. D. Rosa, C. Talotta, A. Rescifina, G. Floresta, A. Soriente, C. Gaeta, P. Neri, Angew. Chem. Int. Ed. 2020, 59, 811-818.

9 E. S. Barrett, T. J. Dale, J. Rebek, Jr., J. Am. Chem. Soc. 2007, 129, 3818-3819.

10 (a) S. Horiuchi, H. Tanaka, E. Sakuda, Y. Arikawa, K. Umakoshi, Chem. Eur. J. 2016, 22, 17533-17537; (b). S. Horiuchi, H. Tanaka, E. Sakuda, Y. Arikawa, K. Umakoshi, Dalton. Trans. 2019, 48, 5156-5160.

11 T. Kai, M. Kishimoto, M. Akita, M. Yoshizawa, Chem. Commun. 2018, 54, 956-959.

12 N. K. Beyeh, M. Kogej, A. Åhman, K. Rissanen, C. A. Schalley, Angew. Chem. Int. Ed. 2006, 45, 5414-5418.
13 For recent reviews on Ir complexes having $\mathrm{N}^{\wedge} \mathrm{N}$ and $\mathrm{N}^{\wedge} \mathrm{C}$ chelating ligands, see: S. Ladouceur, E. Zysman-Colman, Eur. J. Inorg. Chem. 2013, 2985-3007.

14 The UV-Vis absorption spectrum of $[\mathbf{3}]^{+}$in the presence of $\mathbf{2 a}$ did not alter significantly, indicating that the absorption property of $[3]^{+}$is insensitive for the modulation of local environment around [3$]^{+}$even after encapsulation.

15 The nonradiative rate constants $\left(k_{\mathrm{nr}}\right)$ were estimated using an equation as follows: $\Phi=k_{\mathrm{r}} /\left(k_{\mathrm{r}}+k_{\mathrm{nr}}\right)=k_{\mathrm{r}} \tau$.

16 A. Galan, P. Ballester, Chem. Soc. Rev., 2016, 45, 1720-1737.

17 The size of anion are listed in the literature, see: J. K. Clegg, J. Cremers, A. J. Hogben, B. Breiner, M. M. J. Smulders, J. D. Thoburn, J. R. Nitschke, Chem. Sci., 2013, 4, 68-76.

18 Several solvent molecules $\left(\mathrm{CHCl}_{3}: 75 \AA^{3}\right)$ were also encapsulated together with the guests.

19 S. J. Pike, J. J. Hutchinson, C. A. Hunter, J. Am. Chem. Soc. 2017, 139, 6700-6706.

20 G. E. Schneider, H. J. Bolink, E. C. Constable, C. D. Ertl, C. E. Housecroft, A. Pertegàs, J. A. Zampese, A. Kanitz, F. Kessler, S. B. Meier, Dalton Trans., 2014, 43, 1961-1964.

21 The emission band showed a red-shift and the quantum yield decreased upon an addition of TBA salt into the solution of host-guest complex: see ref 10 a.

22 The entapped $\mathrm{BF}_{4}^{-}$clearly appeared at $-142 \mathrm{ppm}$ in the ${ }^{19} \mathrm{~F}$ NMR (Figure S8). This ${ }^{19} \mathrm{~F}$ NMR result clearly revealed that the counter anion was also trapped together with the Ir complex cation within the capsule.

23 The ${ }^{19} \mathrm{~F}$ NMR spectra of [3]X $\left(\mathrm{X}^{-}=\mathrm{BF}_{4}^{-}, \mathrm{PF}_{6}{ }^{-}\right.$and $\left.\mathrm{OTf}^{-}\right)$ showed no new peak before heating (Figure S8b, S11b, and $\mathrm{S} 13 \mathrm{~b})$. These observations suggest that the anions are not encapsulated within the capsule but bound with outer surface of the capsule. 